\title{
Evaluation of myocardial alterations using the enzymatic profile of elderly long-distance runners
}

\author{
C. A. Souza • L. E. Garcez-Leme
}

Received: 1 June 2006 / Accepted: 19 July 2006 / Published online: 22 August 2006

(C) EGREPA 2006

\begin{abstract}
Elderly population often is encouraged to practice sports in preventing cardiovascular diseases. However, evidences exist that intense physical efforts are related with a higher risk for acute myocardial infarction and sudden death. Biological markers for myocardial injury was analyzed in a group of 15 elderly athletes without a history of coronary artery disease, who participated in the 77th International Sao Silvestre race $(15,000 \mathrm{~m})$ in Sao Paulo City. A statistical difference was observed between total CPK activity levels before the run, immediately after the run, and some time later. Similar results were observed in the concentration of CK-MB mass. The cardiac troponin I (TnI-c) levels remained unchanged and within normal limits during the same time periods. The results of the present study showed no evidence of myocardial injury in elderly subjects without a history of coronary artery disease after participating in long-distance runs, as confirmed by the analysis of TnI-c levels. The increase in total CPK activity levels and the concentration of CK-MB mass do not represent myocardial injury in these subjects.
\end{abstract}

Keywords Athletes $\cdot$ Ageing $\cdot$ Sports $\cdot$ Myocardium . Enzymes

C. A. Souza $(\bowtie) \cdot$ L. E. Garcez-Leme

Orthogeriatric Group, Department of Orthopedics and

Traumatology, Faculty of Medicine,

University of Sao Paulo (DOT/FMUSP),

Rua Professor Ovídio Pires de Campos, 333, Hall $3^{\circ}$ Andar CEP,

Sao Paulo 05403-902, Brazil

e-mail: claudio.a.souza@terra.com.br

\section{Introduction}

The benefit resulting from the practice of physical exercises is not exempt from risks $[1,7,12,16]$ and an increase in the risk for acute myocardial infarction and sudden death while exercising or within the subsequent hour.

The detection, by serologic markers, of myocardial ischemic injuries in patients subjected to intense physical exertion presents some limitations due to the elevation in serum levels of creatine phosphokinase MB-isoenzyme (CK-MB) [15] due to an increase in its level in the skeletal musculature $[2,17]$.

The solution to this problem is the analysis of the serum levels of troponins, regulatory proteins found in cardiac and skeletal myocytes that modulate the actinmyosin interaction [6].

We found a few articles in the literature showing increases in the cardiac troponin levels of young subjects after highly intensive sports activities such as marathons, ultra marathons, and Ironman-type triathlons, some of them performed at high altitudes $[3,5,9,11,13,14]$.

In the search to analyze this risk in elderly patients, the only article investigating the specific behavior of enzymatic changes was the study by Lucía et al. [10], who found no changes in cardiac troponin I levels during the Madrid Marathon.

Under these conditions, we proposed to study the enzymatic profile of normal elderly subjects after long-distance runs such as the São Silvestre International street race $(15,000 \mathrm{~m})$.

\section{Materials and methods}

This was a transversal study to evaluate athletes more than 60 years old who participated in the Sao Silvestre 
International street race $(15,000 \mathrm{~m})$ held in Sao Paulo city (Brazil) on December 31, 2001.

Of a group of 114 elderly athletes who had participated in that marathon run in the previous year and were part of a cohort of a follow-up health study of elderly athletes in the Institute of Orthopedics and Traumatology of the Clinics Hospital of the Faculty of Medicine of the University of Sao Paulo (IOT-HC-FMUSP), 15 male athletes aged more than 60 years were invited and accepted participating in this study.

The inclusion criteria adopted were the following:

1. A regularly active athlete

2. Be part of the cohort of a follow-up health study of elderly athletes in the IOT-HC-FMUSP.

3. 60 years old or over

4. Male sex

5. Intend to participate in the 77th International Sao Silvestre Race

6. Have no known history of ischemic coronary disease

7. Willing to sign a free informed consent form

8. Have no clinically uncompensated systemic disease.

Participants were subjected to ergometric and spyrometric tests before participation in the run. All results were negative for coronary ischemia.

Methods

After reading and signing the informed consent form, the volunteers started the protocol stages as follows:

Stage 1: Sample collection of whole blood by peripheral venous puncture of the forearm, 5 days before the marathon

Stage 2: Collection of a new sample of whole blood by peripheral venous puncture of the forearm immediately after the end of the marathon

Stage 3: Sample collection of whole blood by peripheral venous puncture of the forearm, 2 days after the marathon run.

Sample collection was performed using the BD Vacutainer, a vacuum-based sampling system by Becton, Dickinson and Company consisting of Vacutainer needles and needle adapters and BD Vacutainer tubes containing clot-activating gel. After complete retraction of the clots, the sample was centrifuged for $20 \mathrm{~min}$ after which the serum was separated and frozen at $-20^{\circ} \mathrm{C}$.

The CPK activity measurement was performed using a multiparametric automated random-access biochemistry analyzer, the Cobas Integra 700 integrated analytical unit made by Roche Diagnostics, and absorption photometry at $25^{\circ} \mathrm{C}$ with liquid reagent creatin kinase of Roche Diagnostics.
The CPK MB-isoenzyme mass was determined using an automated random-access immunoassay analyzer called Immulite Turbo made by DPC Diagnostic Product Corporation, and by chemoluminescence using the Turbo CK-MB reagent from the same manufacturer.

Cardiac troponin I was determined also using the automated random-access immunoassay analyzer Immulite Turbo made by the DPC Diagnostic Product Corporation, and by chemoluminescence using the Turbo Troponin I reagent from the same manufacturer.

For the analysis of results, the reference values considered normal were as follows: $\mathrm{CPK}, 10-80 \mathrm{IU} / 1$ at $25^{\circ} \mathrm{C}$; CK-MB mass up to $4.0 \mathrm{ng} / \mathrm{ml}$; and cardiac troponin I up to $1.0 \mathrm{ng} / \mathrm{ml}$.

One of the study participants did not collect sample 2 . Two participants did not collect sample 3. One sample 1 was lost due to laboratory problems.

All data were statistically analyzed using the statistical software for Microsoft Excel named Analyse-it, General and Clinical Laboratory Statistics, version 1.62, from Analyse-it Software.

The research project officially complied protocol and was approved by the Ethics Committee for Analysis of Research Projects of the Clinical Board of the Clinics Hospital and the Faculty of Medicine of the University of Sao Paulo under number 215/02.

\section{Results}

All athletes were male volunteers in the 60-74 year age group (mean age: $65.47 \pm 4.55$ years). The subjects' average weight was $67.40 \pm 10.51 \mathrm{~kg}$ (weight range: $49-88 \mathrm{~kg}$ ). The mean height was $1.66 \pm 0.06 \mathrm{~m}$, ranging between 1.58 and $1.79 \mathrm{~m}$.

Two participants had systemic artery hypertension controlled by medication.

Data regarding the values obtained after the analysis of samples of creatine phosphokinase (CPK), creatine phosphokinase isoenzyme MB mass (CK-MB), and cardiac troponin I (TnI-c) are detailed in Table 1.

The CPK and CK-MB levels obtained immediately after the run were statistically higher than those obtained before

Table 1 Enzymatic values in athletes aged over 60 years

\begin{tabular}{|c|c|c|c|}
\hline Variable & $\begin{array}{l}\text { Before } \\
\text { the run }\end{array}$ & $\begin{array}{l}\text { At the end } \\
\text { of the run }\end{array}$ & At $48 \mathrm{~h}^{\mathrm{a}}$ \\
\hline CPK (IU/1) & $93.3 \pm 27.2$ & $148.9 \pm 37.3$ & $141.8 \pm 31.7$ \\
\hline CK-MB (ng/ml) & $4.993 \pm 0.908$ & $6.950 \pm 0.823$ & $7.838 \pm 1.465$ \\
\hline Troponin I (ng/ml) & $<0.5$ & $<0.5$ & $<0.5$ \\
\hline
\end{tabular}

\footnotetext{
${ }^{a}$ Mean \pm standard error of the mean
} 
the run $(p<0.001)$. The troponin I levels were maintained below $0.5 \mathrm{ng} / \mathrm{ml}$ in all samples collected.

\section{Discussion}

The world literature reports that among young individuals subjected to strenuous exertion, sometimes competing at high altitudes, there may be an increase in the levels of cardiac troponin I and also of cardiac troponin T [4].

In some cases, physical exertion is accompanied not only by an increase in troponin but also by cardiac functional manifestations. Some athletes presented dyspnea, reversible pulmonary hypertension, and increased levels of cardiac troponin I associated with right ventricle dysfunction, as proven by echocardiography [9].

However, some alterations in the cardiovascular system of elderly individuals can promote higher risk for myocardial injuries. The increase of ventricle wall thickness, the increase of tension in the ventricle wall, and prolonged myocardial contraction may result in impaired perfusion of the endocardial cells [8].

It seems that the coronary flow does not change with age, but there are no studies to measure it in elderly individuals without coronary artery disease [4]; this opens the perspective that, under intense physical exertion, small changes in this flow may promote injuries in asymptomatic myocardial cells.

In the single study found in the world literature about myocardial injury in the elderly after long-distance runs, Lucía et al. [10], by analyzing the troponin I levels in elderly people participating in the Madrid Marathon, did not find any evidence of myocardial injury. It is worth noting that the number of participants of both sexes in that single study of an elderly population was ten.

We found significant differences between CPK 1 and CPK 2 samples, showing that although the initial value was high, the test contributed to increase that value. However, when we compared CPK 2 and CPK 3 samples as well as CPK 1 and CPK 2 samples, no statistical differences were observed. This phenomenon may be attributed to the reduced number of subjects participating in the present study, associated to a few disagreeing CPK values, which may have contaminated the sample.

The samples collected before the marathon run showed an increase in the CPK and CK-MB levels. The average of these values and the fact that almost half the athletes presented high CPK and CK-MB levels disagree with the findings published in the literature, where such levels are normal in most samples collected before the marathon run $[3,13]$. Most probably this is because, as reported by the athletes themselves, they had been intensely training until the day before the marathon run. The studies mentioned above estimate that the athletes had reduced their training rhythm 1 week before the marathon run and practiced maintenance exercises only.

We found a pattern of CK-MB increase compared to the initial sample, although the high values were maintained after the run. We believe that the high value found in sample 2 and the maintenance of the result in sample 3 are due to the release of the marker of the myocardial musculature injured during the marathon run, proving the findings shown in the literature.

With such high levels of CPK and CK-MB levels, it is impossible to detect the presence or absence of concomitant myocardial injury by just analyzing these substances; thus, the analysis of cardiac troponin I levels is particularly important to detect myocardial injury in these athletes.

The cardiac troponin I level of the runners admitted in this study did not change in any of the samples and was maintained always below $0.50 \mathrm{ng} / \mathrm{ml}$.

Our findings are close to those reported by Lucía et al. [10]. We observed an expressive increase in the CPK and CK-MB values in the elderly runners, although they ran a shorter distance $(15 \mathrm{~km})$. The cardiac troponin I value was found to be within the normal range, showing that up to the distance they ran the athletes did not present myocardial injury.

\section{Conclusion}

Based on the data obtained in this study, we were able to observe that previously trained elderly people without previous coronary disease did not present signs of myocardial injury during long-distance runs up to the limit of $15 \mathrm{~km}$.

\section{References}

1. Albert CM, Mittleman MA, Chae CU, Lee IM, Hennekens CH, Manson JE (2000) Triggering of sudden death from cardiac causes by vigorous exertion. N Engl J Med 343:1355-1361

2. Apple FS (1999) Clinical and analytical standardization issues confronting cardiac troponin I. Clin Chem 45:18-20

3. Auer J, Punzengruber C, Berent R, Porodko M, Eber B (2001) Elevated cardiac troponin I following heavy-resistance exercise in ostium secundum type-atrial septal defect. Chest 120:1752-1753

4. Cleave P, Boswell TD, Speedy DB, Boswell DR (2001) Plasma cardiac troponin concentrations after extreme exercise. Clin Chem 47:608-610

5. Dávila-Román VG, Guest TM, Tuteur PG, Rowe WJ, Ladenson JH, Jafee AS (1997) Transient right but not left ventricular dysfunction after strenuous exercise at high altitude. J Am Coll Cardiol 30:468-473

6. Hillis GS, Fox KA (1999) Cardiac troponins in chest pain can help in risk stratification (editorial). BMJ 319:1451-1452

7. Ide MR, Belini MAV, Caromano FA (2005) Effects of an aquatic versus non-aquatic respiratory exercise program on the respiratory muscle strength in healthy aged persons. Clinics 60(2):151-158 
8. Lakatta GE (2000) Cardiovascular aging in health. Clin Geriatr Med 16:419-443

9. Laslett L, Eisenbud E, Lind R (1996) Evidence of myocardial injury during prolonged strenuous exercise. Am J Cardiol 78:488-490

10. Lucía A, Morán M, Pérez M, Saborido A, Díaz E, Megías A, Chicharro JL (1999) Short-term effects of marathon running in master runners: no evidence of myocardial injury. Int J Sports Med 20:482-486

11. Mair J, Schobersberger W, Koller A, Bialk P, Villiger B, Frey W, Puschendorf B (1997) Risk for exercise-induced myocardial injury for athletes performing prolonged strenuous endurance exercise. Am J Cardiol 80:543-544

12. Mittleman MA, Maclure M, Tofler GH, Sherwood JB, Goldbrerg RJ, Muller JE (1993) Triggering of acute myocardial infarction by heavy physical exertion - protection against triggering by regular exertion. N Engl J Med 329:1677-1683
13. Neumayr G, Gaenzer H, Pfister R, Sturm W, Schwarzacher SP, Eibl G, Mitterbauer G, Hoertnagl H (2001) Plasma levels of cardiac troponin I after prolonged strenuous endurance exercise. Am J Cardiol 87:369-371

14. Ohman EM, Teo KK, Collins PB, Dowsett DG, Ennis JT, Horgan JH (1982) Abnormal cardiac enzyme responses after strenuous exercise: alternative diagnostic aids. BMJ 285:1523-1526

15. Siegel AJ, Silverman LM, Holman BL (1981) Elevated creatine kinase $\mathrm{MB}$ isoenzyme levels in marathon runners. Normal myocardial scintigrams suggest noncardiac source. JAMA 246:2049-2051

16. Willich SN, Lewis M, Lowell H, Arntz HR, Schubert F, Schroder R (1993) Physical exertion as a trigger of acute myocardial infarction. N Engl J Med 329:1684-1690

17. Young A (1984) Plasma creatine kinase after the marathon - a diagnostic dilemma. Br J Sports Med 18:269-272 